\title{
THE EFFECT OF CALCINATED HYDROXYAPATITE AND MAGNESIUM DOPED HYDROXYAPATITE AS FILLERS ON THE MECHANICAL PROPERTIES OF A MODEL BisGMA/TEGDMA DENTAL COMPOSITE INITIALLY AND AFTER AGING
}

\author{
Tamara Matićl ${ }^{*}$, Maja Ležaja Zebićn ${ }^{2}$ Ivana Cvijović-Alagićc ${ }^{3}$, Vesna Miletić ${ }^{2}$, \\ Rada Petrovićl, Djordje Janaćkovićl, Djordje Veljović ${ }^{1}$ \\ ${ }^{1}$ Faculty of Technology and Metallurgy, University of Belgrade, Karnegijeva 4, \\ 11120 Belgrade, Serbia \\ ${ }^{2}$ School of Dental Medicine, University of Belgrade, Rankeova 4, 11000 \\ Belgrade, Serbia \\ ${ }^{3}$ Institute of Nuclear Sciences "Vinča", University of Belgrade, Mike Petrovića \\ Alasa 12-14, 11001 Belgrade, Serbia
}

Received 04.12.2018

Accepted 17.12.2018

\begin{abstract}
This study aimed to investigate the possibility of modifying model BisGMA/TEGDMA dental composite by substituting $10 \mathrm{wt}$ \% of conventional glass fillers with bioactive fillers based on calcinated nanosized hydroxyapatite (HAp) and Mg-doped hydroxyapatite (Mg-HAp). HAp and Mg-HAp powders were synthesized hydrothermally. Mechanical properties: hardness by Vickers (HV) and flexural strength (Fs) were tested initially and after being stored for 28 days in simulated body fluid (SBF). The experimental composites with HAp and Mg-HAp particles showed no statistically significant difference in HV compared to the control $(p>0.05)$ either initially or after storage. Although mean Fs values of modified composites tested initially were lower $(62 \mathrm{MPa})$ than those of the control (72 MPa), after 28 days of storage in SBF Fs values were greater for modified composites (42 MPa control sample, $48 \mathrm{MPa} \mathrm{HAp}$, and Mg-HAp samples). In vitro bioactivity of BisGMA/TEGDMA composites with HAp and Mg-HAp particles after 28 days in SBF was not detected.
\end{abstract}

Keywords: hydroxyapatite; magnesium; dental composite; mechanical properties

\footnotetext{
* Corresponding author: Tamara Matić, tamaramatic00@gmail.com
} 


\section{Introduction}

In the past decades, dental resin-based composites (RBCs) have been widely used as restorative materials for repairing damaged or decayed tooth structure [1]. They have replaced previously used amalgams, owing to their superior aesthetic properties such as adapting restoration color nuance to the one of the natural teeth. Dental composites typically consist of three main components: the organic matrix (bisphenol A glycerolate dimethacrylate (BisGMA), triethylene-glycol (TEGDMA), etc. resin with added initiators, accelerators, inhibitors, and stabilizers), inorganic filler particles, and the silane coupling agents [2]. While the commercially-used monomers have changed very little and only within the last two decades with the introduction of low-shrinkage, longchain monomers, significant improvements in mechanical properties of dental RBCs have been brought by changes in type, size, and distribution of the inorganic fillers. Polymerization shrinkage, on the other hand, is still a remaining issue. It causes microgap formation at the tooth-restoration margins, enabling clinically invisible penetration of oral fluids and microorganisms toward the dental pulp, known as microleakage. Bacteria (e.g., Streptococcus mutans) metabolize sugars to lactic acid and therefore lowers $\mathrm{pH}$ [3]. Due to a decrease in $\mathrm{pH}$ value, hydroxyapatite in the tooth structure tends to demineralize causing caries [4]. Secondary caries is considered to be the most common reason for restoration failure and replacement [5,6]. Furthermore, bacterial metabolic by-products may cause pulpal inflammation and necrosis resulting in the loss of pulp vitality.

One possible approach to reduce the risk of secondary caries development is to add bioactive agents that promote remineralization of tooth structure through calcium and phosphate ion release. In this regard, a wide range of calcium phosphates $(\mathrm{CaP})$ such as hydroxyapatite (HAp), amorphous calcium phosphate (ACP), tetracalcium phosphate (TTCP) and mono- and dicalcium phosphates (MCPM and DCPA) have been studied as fillers in dental composites [7-18]. Nanostructured calcium-hydroxyapatite (HAp) presents as a desired component in dental materials due to its biocompatibility, bioactivity and chemical similarity to inorganic component of the teeth [19]. Moreover, HAp has intrinsic radio-opaque property and similar hardness to that of teeth [7]. During calcination and sintering, HAp undergoes a phase transition into $\beta$-tricalciumphosphate $(\beta$-TCP) which possesses higher resorb rate [20]. Doping HAp with magnesium ions (Mg-HAp) leads to stabilization of $\beta$-TCP phase during sintering, higher cell proliferation as well as to increased bioactivity, biocompatibility and stronger mechanical properties [21-23]. Furthermore, magnesium plays an essential role in cells such as stimulating cell growth and proliferation [23].

CaP-resin composite materials developed so far were shown to be effective in remineralizing tooth lesions in vitro [24] as well as to inhibit the development of new lesions in situ [17]. Lezaja et al. [25] studied the effect of combining different HAp particles and conventional glass fillers in experimental BisGMA/TEGDMA composites on mechanical properties. It was reported that flexural strength was increased with the addition of HAp, but Vickers hardness decreased. To the best of our knowledge, effects of Mg-doped HAp fillers in dental composites have not been reported so far.

As Mg-HAp has better mechanical properties compared to HAp, this study aimed to investigate the mechanical behavior of BisGMA/TEGDMA dental composites reinforced with conventional glass fillers combined with nano HAp and nano Mg-HAp particles. Based on the previously reported study by Lezaja et al. [25] a total amount of 
73 wt. \% reinforcement filler particles were used, with $10 \%$ substitution with Mg-HAp or HAp calcinated powders. BisGMA/TEGDMA resin filled with only Ba-glass fillers was used as a control. HAp and Mg-HAp powders were obtained hydrothermally and characterized by the X-ray diffraction (XRD) and scanning electron microscopy (SEM) paired with energy dispersive X-ray analysis (EDX). Experimental composites were tested for flexural strength (Fs) and Vickers hardness (HV), initially $24 \mathrm{~h}$ after polymerization and after aging in simulated body fluid (SBF) for 28 days. Bioactivity of the prepared composites was monitored by SEM after being stored in SBF for 28 days.

\section{Materials and methods}

Hydroxyapatite and Mg-doped hydroxyapatite powders synthesis

Nanosized calcium-hydroxyapatite (HAp) and calcium-hydroxyapatite doped with 5 mol.\% magnesium (Mg-HAp) powders were obtained by a previously described modified hydrothermal method [26-28], starting from a solution of $\mathrm{Ca}\left(\mathrm{NO}_{3}\right)_{2} \cdot 4 \mathrm{H}_{2} \mathrm{O}$ $(11.80 \mathrm{~g}), \mathrm{Na}_{2} \mathrm{H}_{2}$ EDTA $2 \mathrm{H}_{2} \mathrm{O}(11.18 \mathrm{~g}), \mathrm{NaH}_{2} \mathrm{PO}_{4} \cdot 2 \mathrm{H}_{2} \mathrm{O}(4.68 \mathrm{~g})$ and urea (12.00 g). For the synthesis of Mg-HAp $5 \mathrm{~mol}$. \% of $\mathrm{Ca}$ was substituted with $\mathrm{Mg}$ ions. As $\mathrm{Mg}$ ion source was used $\mathrm{Mg}\left(\mathrm{NO}_{3}\right)_{2} \cdot 6 \mathrm{H}_{2} \mathrm{O}(0.641 \mathrm{~g})$. The precursor solution was thermally treated in an autoclave at $160{ }^{\circ} \mathrm{C}$ for 3 hours, under $\mathrm{p}=8$ bar. Obtained participates were collected by vacuum filtration, flushed with deionized (DI) water and dried at 105 ${ }^{\circ} \mathrm{C}$. HAp and Mg-HAp powders were then calcinated for 4 hours at $1000{ }^{\circ} \mathrm{C}$ (heating rate of $\left.20^{\circ} \mathrm{C} / \mathrm{min}\right)$.

\section{Composite paste preparation}

Experimental composites were prepared by a previously reported method [25] by mixing equal wt. \% of BisGMA and TEGDMA resins with 0.2 wt. \% of camphorquinone (CQ) and $0.8 \mathrm{wt}$ \% of 2-(dimethyl)ethyl methacrylate (DMAEMA). All ingredients were purchased from Sigma-Aldrich Chemie GmbH, Munich, Germany. The content of fillers in experimental groups is shown in Table 1. Control conventional fillers were silanated barium glass particles with the average size of $0.7 \mu \mathrm{m}$ (BaGlass, $33 \% \mathrm{BaO}$, Esstech Inc, USA). HAp and Mg-HAp particles were used to replace $10 \mathrm{wt}$. $\%$ of glass fillers in experimental groups.

Table 1. Composition of Experimental Composites.

\begin{tabular}{lccc}
\hline Group & $\begin{array}{c}\text { Silanated } \\
\text { Barium Glass } \\
(\text { wt. \%) }\end{array}$ & $\begin{array}{c}\text { Filler content } \\
\text { HAp particles } \\
\text { (wt. \%) }\end{array}$ & $\begin{array}{c}\text { Mg-HAp } \\
\text { particles } \\
\text { (wt. \%) }\end{array}$ \\
\hline Control & 73 & $/$ & $/$ \\
Hap & 65.7 & 7.3 & $/$ \\
Mg-HAp & 65.7 & $/$ & 7.3 \\
\hline
\end{tabular}

\section{Sample preparation and storage for mechanical testing}

For Vickers hardness (HV) test, ten samples per group were prepared by using disc-shaped plastic molds, $5 \mathrm{~mm}$ in diameter and $2 \mathrm{~mm}$ deep. A Mylar strip was placed on a $1 \mathrm{~mm}$ thick glass slide, on top of which the mould was positioned and filled with composite. Top of the mould was covered with another strip and pressed with a glass slide to eliminate excess material and form a flat surface. Samples were then light-cured 
with a light-emitting diode light-curing unit (LEDition, Ivoclar Vivadent, Schaan, Liechtenstein) at an intensity of $800 \mathrm{~mW} / \mathrm{cm}^{2}$ for $40 \mathrm{~s}$ through the Mylar strip and the glass slide.

For Fs testing, ten samples per group were prepared according to the ISO 4049:2000 standard in steel molds with internal dimensions $2 \mathrm{~mm} \times 2 \mathrm{~mm} \times 25 \mathrm{~mm}$. Each sample was cured for $4 \times 40 \mathrm{~s}$ : in the middle, on the one end of the mold, then another end and lastly by moving the LED light-curing unit from one end to another and back.

The samples were stored in DI water and kept in the incubator at $37{ }^{\circ} \mathrm{C}$ during the first $24 \mathrm{~h}$, according to the ISO 2049:2000 standard. Afterward five samples per group were tested for $\mathrm{HV}$ and Fs, and the rest of the samples were immersed in $10 \mathrm{~cm}^{3}$ Kokubo simulated body fluid (SBF) [29], the composition of which is shown in Table 2, and stored for 28 days in a water bath at $37{ }^{\circ} \mathrm{C}$. SBF solution was replaced every five days. Another HV and Fs tests were carried out after aging for 28 days in SBF.

Table 2. Composition of Kokubo simulated body fluid

\begin{tabular}{llllccccc}
\hline Ion & $\mathrm{Na}^{+}$ & $\mathrm{K}^{+}$ & $\mathrm{Ca}^{2+}$ & $\mathrm{Mg}^{2+}$ & $\mathrm{Cl}^{-}$ & $\mathrm{HCO}_{3}^{-}$ & $\mathrm{HPO}_{4}{ }^{2-}$ & $\mathrm{SO}_{4}{ }^{2-}$ \\
\hline $\mathrm{c}(\mathrm{mg} / \mathrm{dm} 3)$ & 142.0 & 5.0 & 2.5 & 1.5 & 147.8 & 4.2 & 1.0 & 0.5 \\
\hline
\end{tabular}

\section{Characterization}

$X$-ray Diffraction Analysis

Phase composition of HAp and Mg-HAp powders were determined by X-ray diffraction analysis (XRD) conducted on Ital Structure APD 2000 X-ray diffractometer with $\mathrm{CuK} \alpha$ radiation $(1.54 \AA)$ in the $2 \theta$ angle ranging from $20^{\circ}$ to $60^{\circ}$ with a scan step $0.02^{\circ}$.

Scanning electron microscopy and energy dispersive $X$-ray analysis

A scanning electron microscope (Tescan FE-SEM Mira 3 XMU, Tescan a.s., Brno, Czech Republic) was employed to characterize the morphology of the powders and the cross section of the experimental composites, operated at $20 \mathrm{keV}$. All samples were coated with gold using a sputter coater (Polaron SC503, Fisons Instruments, Ipswich, UK) before SEM analysis. To determine elemental composition energy dispersive X-ray (EDX) analysis was performed on Oxford Inca 3.2 coupled with SEM Jeol JSM 5800, operated at $20 \mathrm{keV}$.

Hardness by Vickers

Hardness by Vickers (HV) was measured by applying $500 \mathrm{~g}$ load for $5 \mathrm{~s}$ on an HV test machine (Buehler Indentament 1100 series, Buehler, Lake Bluff, IL). Three indentations were made on the bottom, non-irradiated side of each sample.

Flexural strength

Flexural strength (Fs) was measured using a three-point bending setup and a universal testing machine (Force Gauge PCE-FM200, Southampton, United Kingdom) at $1 \mathrm{~mm} / \mathrm{min}$ speed until fracture. Fs was determined using the equation:

$$
F_{S}=\frac{3 F l}{2 b h^{2}}
$$


where $F$ is the maximum load measured before fracture, $l$ is a distance between supports $(20 \mathrm{~mm}), h$ is the sample height, and $b$ is the sample width.

In vitro bioactivity

Apatite-forming ability of the composites was evaluated in Kokubo simulated body fluid (SBF). HAp, Mg-HAp, and control samples were soaked in $10 \mathrm{~cm}^{3} \mathrm{SBF}$ at $37{ }^{\circ} \mathrm{C}$ for 28 days. SBF solution was replaced every five days. After being soaked, samples were removed from SBF, gently rinsed with DI water three times, dried at room temperature for $24 \mathrm{~h}$ then stored in a desiccator. Morphology of the samples' surface was examined by SEM (Tescan FE-SEM Mira 3 XMU, Tescan a.s., Brno, Czech Republic).

\section{Statistical analysis}

Statistical analysis was performed in the software package Minitab Express (Minitab Inc. State College, PA, USA). Data for HV were analyzed using two-way analysis of variance (ANOVA) for the factors "materials" and "time" with the interaction between the two factors included. The level of significance was set at 0.05.

\section{Results}

\section{EDX analysis}

Results of the EDX analysis of the powders are shown in Table 3. The results present average arithmetical value of three measurements of different surface areas of the sample at the 1000 times magnification. The presence of magnesium as doping species in Mg-HAp sample was confirmed. The $\mathrm{Ca} / \mathrm{Pa}$ ratios in $\mathrm{HAp}$, and $\mathrm{Mg}-\mathrm{HAp}$ powders were less than the stoichiometric ratio of hydroxyapatite (1.67), implying that obtained hydroxyapatites were calcium-deficient, and expected to undergo a phase transition into $\beta$-tricalcium phosphate $(\beta-\mathrm{TCP})$ when heated.

Table 3. Elemental composition of obtained powders

\begin{tabular}{lllll}
\hline Sample & Ca, at.\% & $\mathrm{P}$, at.\% & $\mathrm{Mg}$, at.\% & $\mathrm{Ca} / \mathrm{P}$ ratio \\
\hline HAp & 12.84 & 8.64 & - & 1.49 \\
Mg-HAp & 11.59 & 8.00 & 0.27 & 1.45 \\
\hline
\end{tabular}

\section{XRD analysis}

The XRD patterns of the HAp and Mg-HAp samples before calcination show peaks suggesting that monophasic calcium-hydroxyapatite powders were obtained (Fig. $1 \mathrm{a}, \mathrm{b})$ according to JCPDS 9-432. After calcination at $1000{ }^{\circ} \mathrm{C}$ XRD patterns suggest that hydroxyapatite (HAp) underwent a phase transition into $\beta$-tricalcium phosphate $(\beta-$ TCP) (Fig. 1 c,d). In the case of calcinated HAp sample (Fig. 1c) HAp phase was dominant, and a small amount was transformed into $\beta$-TCP, while in the case of calcinated Mg-HAp sample biphasic powder with dominant $\beta$-TCP phase was obtained (Fig. 1d). The increased amount of $\beta$-TCP phase may be contributed to the presence of $\mathrm{Mg}$ ions in the Mg-HAp sample. 

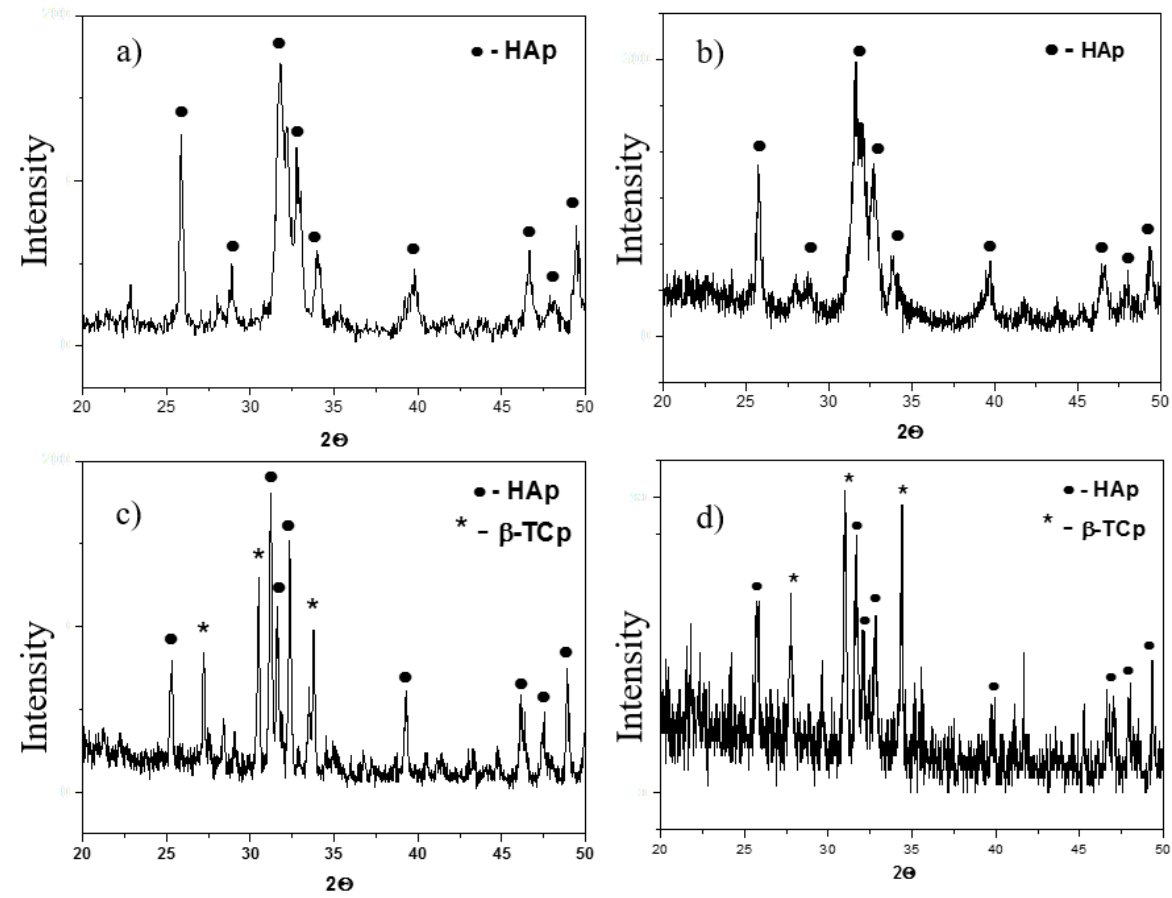

Fig. 1. XRD patterns of a) HAp powder; b) Mg-HAp powder; c) HAp calcinated at 1000 ${ }^{\circ} \mathrm{C}$; d) $\mathrm{Mg}$-HAp calcinated at $1000{ }^{\circ} \mathrm{C}$.

\section{SEM analysis}

The SEM micrographs of the HAp and Mg-HAp powders (Fig. 2 a,b) show that in both cases relatively uniform spherical agglomerates were obtained. In the case of HAp sample (Fig. 2a), these spherical particles are around 1,5 $\mu \mathrm{m}$ in size and consist of nano-rods. The spherical agglomerates of Mg-HAp (Fig. 2b) are noticeably rounder with more densely packed nano-rods. After calcination in both samples agglomerates were reduced in size and densified due to grain formation (Fig. 2 c,d). Fig. 3 shows cross sections of experimental composites with typical microstructure for dental composites. In the control sample conventional Ba-glass particles are visible in BisGMA/TEGDMA resin (Fig. 3a). In the case of modified experimental composites, round Mg-HAp and HAp particles are also present, relatively uniformly distributed inorganic matrix with no tendency to agglomerate (Fig. $3 \mathrm{~b}$ and $3 \mathrm{c}$ respectively). 

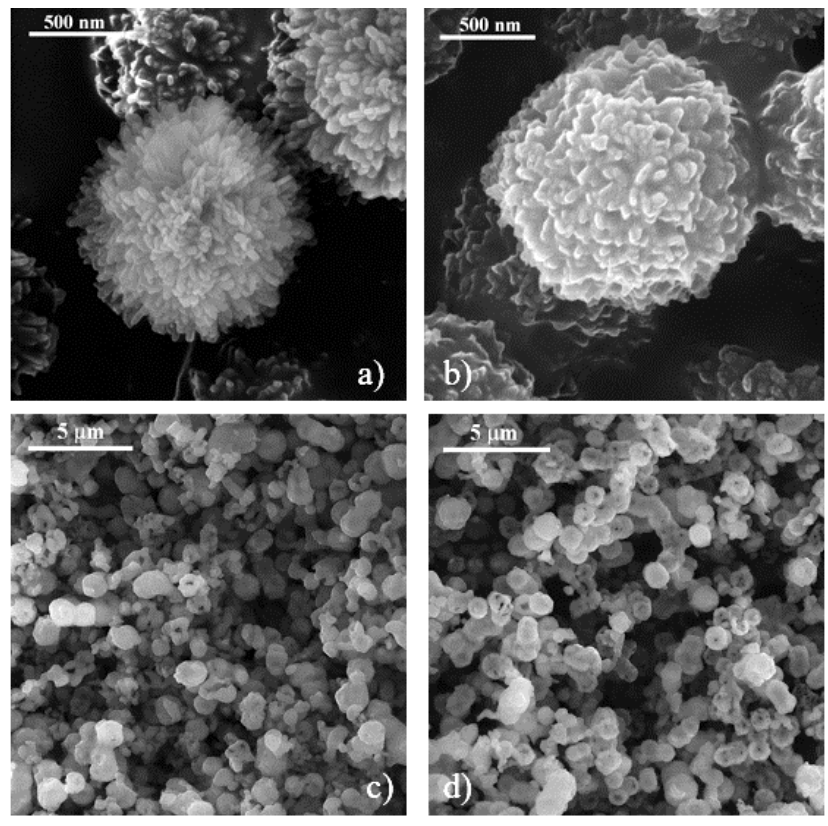

Fig. 2. SEM images of a) HAp particles; b) Mg-HAp particles; c) calcinated HAp powder; d) calcinated Mg-HAp powder.
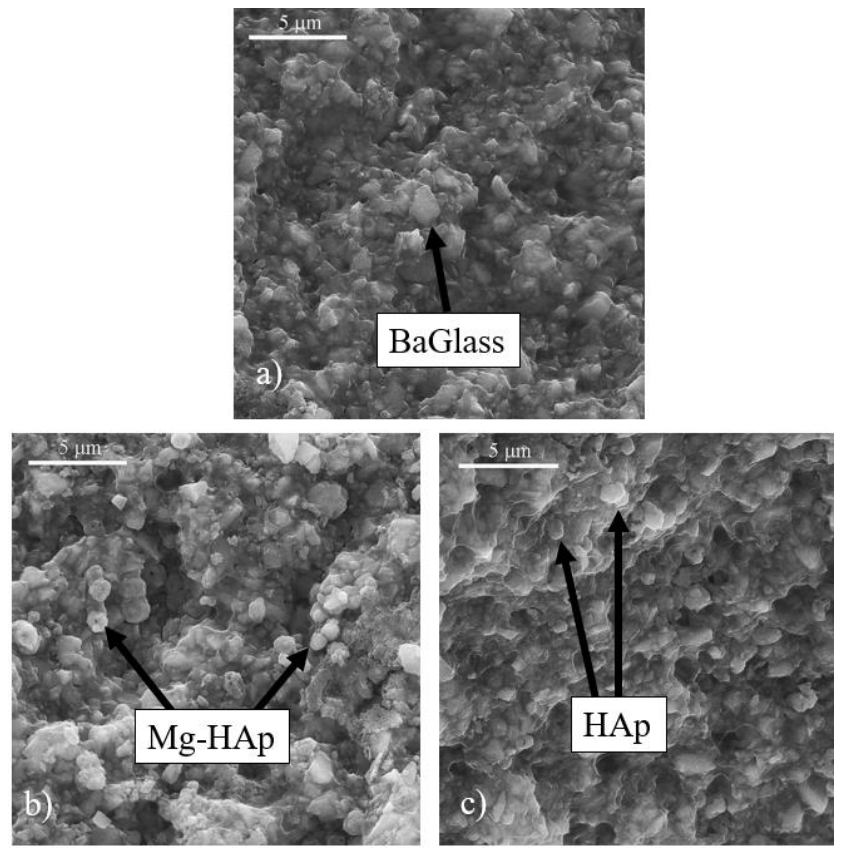

Fig. 3. SEM images of cross section of a) control sample; b) Mg-HAp sample; c) HAp sample. 
In vitro bioactivity

In vitro bioactivity is defined as the ability of a material to form apatite layer on its surface when submerged in SBF. Dental composites containing bioactive CaP particles were reported to be in vitro bioactive [7, 18]. Santos et al. [7] have shown that dental composites containing silanized hydroxyapatite particles are in vitro bioactive after being stored for 4 weeks in SBF. Aljabo et al. [18] have monitored in vitro bioactivity of dental composites containing equal masses of $\beta$-tricalcium phosphate $(\beta$ TCP) and monocalcium phosphate monohydrate (MCPM) for 12 weeks in SBF. Experimental composites containing HAp and Mg-HAp particles tested in this study did not show any bioactive phenomenon after being stored for 28 days in SBF (Fig. 4). This is probably caused by the high quantity of Ba-glass filler, which is not bioactive.
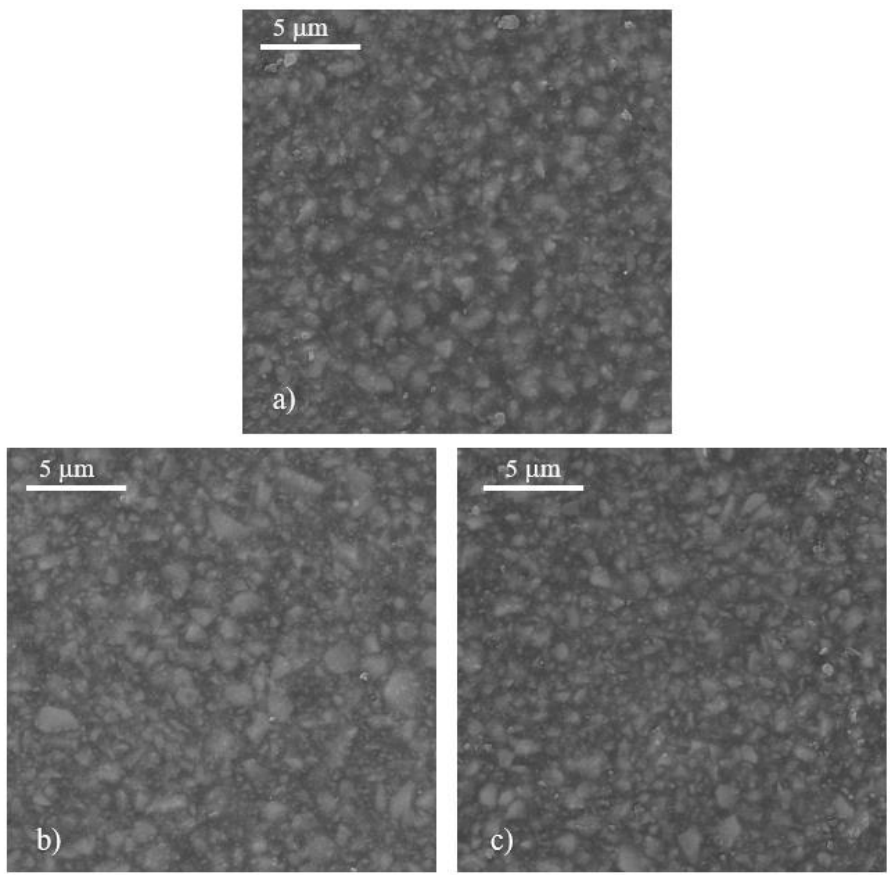

Fig. 4. Sample surface after 28 days in SBF a) control; b) Mg-HAp sample; c) HAp sample.

\section{Hardness by Vickers $(H V)$}

HV test results are shown in Fig. 5 present average arithmetical value for five samples per group, tested initially and after aging in SBF for 28 days. Two-way ANOVA showed statistically significant differences for the factor "material" $(\mathrm{p}=0.0149)$, but not for the factor "time" $(\mathrm{p}=0.2877)$. The interaction between the two factors was not significant $(\mathrm{p}=0.1838$ ) indicating no differences for each material at two periods (initially and after 28 days). Additional one-way ANOVA with Tukey's post hoc test was performed to analyze the differences between materials at both periods separately. Only marginal statistical significance was found between Mg-HAp and HAp groups initially $(\mathrm{p}=0.05)$, where mean $\mathrm{HV}$ values for composite reinforced with $\mathrm{Mg}$ HAp particles were $12 \%$ greater than those for HAp reinforced composite. As shown in 
Fig. 5, substituting 10 wt. \% of conventional glass fillers with HAp and Mg-HAp particles had no statistically significant difference $(\mathrm{p}>0.05)$ either initially or after storage. This is following a previously reported paper by Lezaja et al. [25].

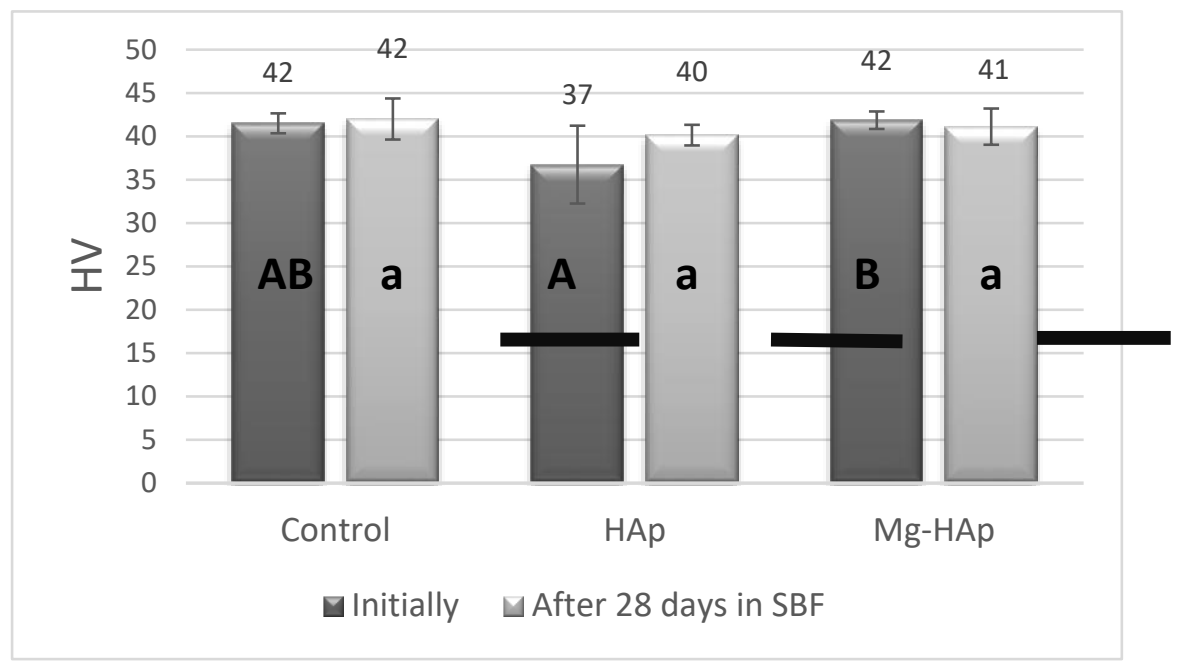

Fig. 5. Hardness by Vickers of experimental composites; uppercase letters refer to the groups initially; lower case letters refer to the groups after 28 days. Groups that share the same letter are not significantly different $(p>0.05)$. Bar indicates no significant difference between the two periods for each group $(p>0.05)$.

\section{Flexural strength (Fs)}

Results of flexural strength (Fs) testing initially and after being stored for 28 days in SBF are shown in Fig. 6 and present average arithmetical values for five samples per group. Statistical analysis was not performed on Fs values due to an insufficient number of data and high standard deviation values. As shown in Fig. 6, the addition of HAp and $\mathrm{Mg}-\mathrm{HAp}$ particles decreased flexural strength of composites tested initially (74 MPa for control, $62 \mathrm{MPa}$ for HAp sample, $61 \mathrm{MPa}$ for Mg-HAp sample). The decrease in Fs after aging is common for all composite samples and following previously reported papers $[14,25,30]$. Fs was less affected by aging when Mg-HAp or HAp particles were added. Control samples decreased in the mean value of Fs by $43 \%$, while mean Fs values for HAp and Mg-HAp samples decreased by $23 \%$. After 28 days stored in SBF, modified composites had higher mean values of flexural strength by $12 \%$ than the control. 


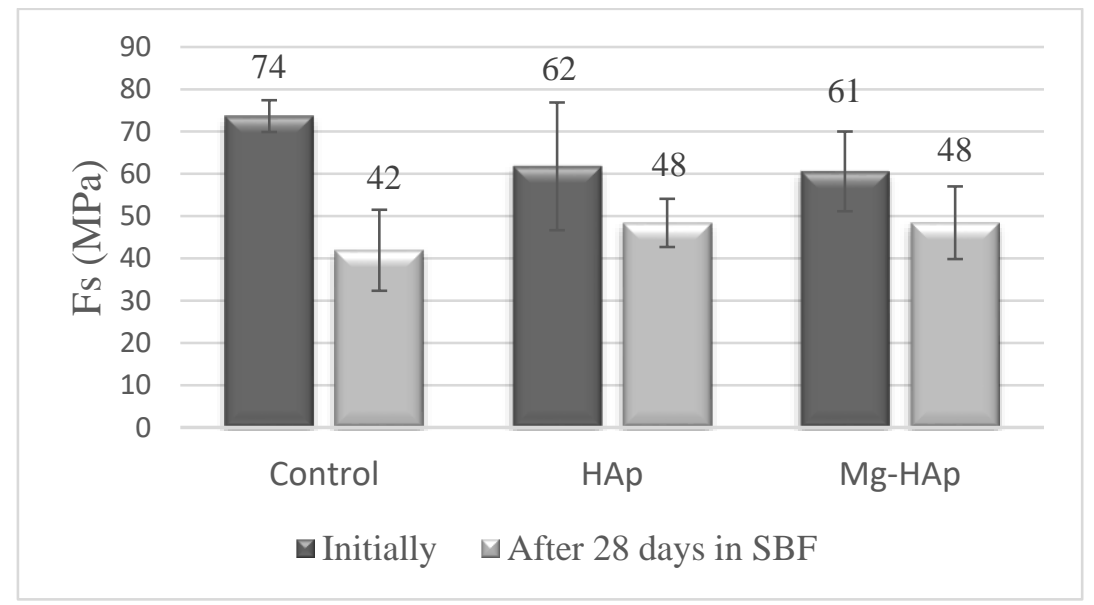

Fig. 6. Flexural strength of experimental composites.

\section{Conclusion}

Substitution of 10 wt. \% conventional glass fillers with HAp and Mg-HAp powders had no statistically significant difference in hardness by Vickers $(p>0.05)$ either initially or after storage in SBF for 28 days. The addition of HAp and Mg-HAp particles decreased flexural strength of composites tested initially, but it improved the stability of composites when stored in SBF. After being stored in SBF for 28 days, control sample mean values of Fs decreased by $43 \%$, while mean Fs values for HAp and Mg-HAp samples decreased by $23 \%$. Modified composites had $12 \%$ higher flexural strength than the control after 28 days. In vitro bioactivity of BisGMA/TEGDMA composites with HAp and Mg-HAp particles after 28 days in SBF was not detected.

\section{Acknowledgment}

The authors wish to acknowledge the financial support for this research from the Ministry of Education, Science and Technological Development, the Republic of Serbia through the project III45019 and ON172007.

\section{References}

[1] R.L. Bowen: J Am Dental Assoc, 66 (1963) 57-64.

[2] L. Chen, Q. Yu, Y. Wang, H. Li: Dent Mater, 27 (2011) 1187-1195

[3] I.A. Mjör, O.F. Toffentti: Quintessence Int, 31 (2000) 165-179

[4] P.H. Keyes: J Am Dent Assoc, 76 (1968) 1357-1373

[5] I.A. Mjör, J.E. Dahl, J.E. Moorhead: Acta Odontol Scand, 60 (2002) 25-28.

[6] M. Bernardo, H. Luis, M.D. Martin, B.G. Leroux, T. Rue, J. Leitao, et al.: J Am Dent Assoc, 138 (2007) 775-783.

[7] C. Santos, Z.B. Luklinska, R.L. Clarke, K.W. Davy: J Mater Sci Mater Med, 12 (2001) 565-573.

[8] L.C. Natale, M.C. Rodrigues, Y. Alania, M.D.S. Chiari, L.C.C. Boaro, O.Vega, R.R. Braga: J Mech Behav Biomed Mater, 84 (2018) 161-167 
[9] D. Skrtic, J.M. Antonucci, A.W. Hailer, S. Takagi, E.D. Eanes: J Dent Res, 75 (1996) 1679-1686

[10] D. Skrtic, J.M. Antonucci, E.D. Eanes: Dent Mater, 12 (1996) 295-301.

[11] H.H. Xu, M.D. Weir, L. Sun: Dent Mater, 25 (2009) 535-542.

[12] H. Zhang, M. Zhang et. al., In: Proceedings BMEI 2010. 2010, 1640-1644.

[13] Y. Alania Y, M.D.S. Chiari, M.C. Rodrigues, V.E. Arana-Chavez, A.H.A.Bressiani, F.M Vichi, R.R. Braga: Dent Mater, 32 (2016) 374-381.

[14] M.D.S Chiari, M.C. Rodrigues, T.A. Xavier, E.M.N. de Souza, R.R. Braga: Dent Mater, 31 (2015) 726-733

[15] M.C. Rodrigues, L. Natale, V.E Arana-Chaves, R.R. Braga: J Biomed Mater Res B Appl Biomater, 103 (2015) 1670-1678

[16] H. Xu, L. Sun, M. Weir, J. Antonucci, S. Takagi, L. Chow, et al.: J Dent. Res, 85 (2006) 722-727.

[17] M.A.S. Melo, M.D. Weir, L.K.A. Rodrigues, H.H.K. Xu: Dental Mater, 29 (2013) 231-240

[18] A. Aljabo, E.A. Abou Neel, J.C. Knowles, A.M. Young: J Mater Sci and Eng, 60 (2016) 285-292

[19]Dj. Janackovic, I. Balac, B. Bugarski, I. Cosic, M. Dramicanin, D. Djordjevic, N. Filipovic, N. Ignjatovic et al., Biomaterijali, first ed., Institut tehničkih nauka SANU, Beograd, 2010, 513-546 .

[20] M.A. Lopez, F.J. Monteiro, J.D. Santos: Biomaterials, 20 (1999) 2085-2090.

[21] W. Hue, K. Dahquist, A. Banarjee, A. Bandyopadhyay, S. Bose: J Mater Sci Mater Med, 19 (2008) 2669-2677

[22] H.S. Ryu, K.S. Hong, J.K. Lee, D.J. Kim, J.H. Lee, et. al.: Biomaterial, 25 (2004) 393-401.

[23] M. Shahrezae, M. Raz, S. Shishehbor, F. Moztarzadeh et. al.: Silicon, 10 (2018) 1171-1179

[24] S.E. Langhorst, J.N. O'Donnell, D. Skrtic: Dent Mater, 25 (2009) 884-891

[25] M. Lezaja, Dj. Veljovic, B. Jokic, I. Cvijovic-Alagic, M. Zrilic, V. Miletic. J Biomed Mater Res B: Appl Biomater, 101 (2013) 1469-1476.

[26] Dj. Janackovic, I. Petrovic-Prelevic, Lj. Kostic-Gvozdenovic, R. Petrovic, V. Jokanovic, D. Uskovic: Key Eng Mater, 203 (2001) 192-195.

[27]Dj. Veljovic, E. Palcevskis, A. Dindune, S. Putic, I. Balac, R. Petrovic, Dj. Janackovic: J Mater Sci, 45 (2010) 3175-3183.

[28] B. Jokic, D. Radmilovic, D. Drmanic, S. Drmanic, R. Petrovic, Dj. Janackovic: Ceram Int, 37 (2011) 167-173.

[29] T. Kokubo, H.Takadama: J Biomater, 27 (2006) 2907-2915.

[30] S. Hahnel , A. Henrich, R. Burgers, G. Handel, M. Rosentritt: J Op Dent, 35 (2010) 412-419.

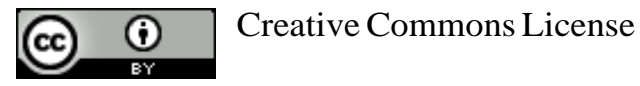

This work is licensed under a Creative Commons Attribution 4.0 International License. 